\title{
ANÁLISE DA TENDÊNCIA ESPACIAL DO DESCONTÍNUO FLUVIAL DO CÓRREGO DO LIMOEIRO, MUNICÍPIO DE PRESIDENTE PRUDENTE/SP
}

\section{ANALYSIS OF THE DISCONTINUUM LIMOEIRO STREAM SPATIAL TENDENCY IN PRESIDENTE PRUDENTE/SP}

\author{
Carolina Altavini de Abreu ${ }^{1 ;}$ Renata Ribeiro de Araújo²
}

Universidade Estadual Paulista - UNESP, Departamento de Planejamento, Urbanismo e Ambiente, Presidente Prudente, SP. Pesquisa financiada pela Fundação de Amparo á Pesquisa do Estado de São Paulo - FAPESP. e-mail: reribeiro@fct.unesp.br

RESUMO - O presente artigo teve como objetivo a análise do Descontínuo Fluvial no córrego do Limoeiro, Presidente Prudente/SP, através do monitoramento limnológico em três seções amostrais, sendo duas seções no córrego do Limoeiro, uma à montante e outra à jusante da confluência com o córrego do Veado, e uma seção no córrego do Veado à montante da confluência com o córrego do Limoeiro. As variáveis limnológicas monitoradas foram o oxigênio dissolvido, $\mathrm{pH}$, condutividade elétrica, nitrato, turbidez, temperatura da água e vazão. Em protocolos laboratoriais foram determinados o material em suspensão total, fósforo total, dissolvido e ortofosfato. Os resultados do monitoramento foram tabulados e aplicou-se a Análise de Componentes Principais. Os resultados obtidos indicaram que o Córrego do Veado provoca uma ruptura no gradiente natural do canal principal, o Córrego do Limoeiro.

Palavras-chave: córrego do Limoeiro; Presidente Prudente; descontínuo fluvial.

ABSTRACT - This article aimed to analyze the Discontinuous River in the Limoeiro stream, Presidente Prudente/SP city, through limnological monitoring at three sampling sections, two sections in the Limoeiro stream, one upstream and one downstream of the confluence with the Veado stream, and a section in the Veado stream upstream of the confluence with Limoeiro stream. The limnological variables determined were dissolved oxygen, $\mathrm{pH}$, conductivity, nitrate,

Recebido em: 19/08/2014 Revisado em: 07/09/2014 Aprovado em: 10/09/201 turbidity, water temperature and flow. In lab protocols the material in full suspension, total and dissolved phosphorus, and orthophosphate were determined. Monitoring results were tabulated and the principal component analysis. The results indicate that the Veado stream causes a disruption in the natural gradient of the main channel, the Limoeiro stream.

Keywords: Limoeiro stream; Presidente Prudente; the river discontinuum. 


\section{INTRODUÇÃO}

O Brasil é extremamente favorecido em relação a abundancia de água, pois possui cerca de $20 \%$ do total de água doce do planeta (GOMES et al., 2005), este grande potencial hídrico deve então ser visto como um capital ecológico de inestimável importância e fator competitivo fundamental ao desenvolvimento socioeconômico sustentado (NAIME \& FAGUNDES, 2005). Apesar disso, a água não vem recebendo a importância devida na gestão urbana do país e os danos causados aos cursos d'água repercutem na qualidade de vida da sociedade (CERQUEIRA et al., 2005).

Uma característica marcante dos rios brasileiros, que são a principal fonte de abastecimento da sociedade, é a grande quantidade de carga poluente recebida através de seus afluentes, majoritariamente daqueles que atravessam o perímetro urbano (MADRUGA et al., 2008 apud por TERRA et al., 2010).

Um dos fatores que contribui para essa condição é a característica brasileira do adensamento de moradias irregulares em áreas de preservação permanente, prejudicando a integridade humana e as condições ambientais da área, uma vez que nessas circunstâncias é provável a contaminação do curso d'água (SÁNCHEZ; BELLO apud FELICIDADE et al., 2001). Outros fatores importantes que contribuem para essa condição são os despejos clandestinos de resíduos industriais nos corpos d'águas urbanos. Isso acontece porque os processos que ocorrem na água estão minuciosamente ligados e, portanto, a inserção de qualquer substância na água provoca alterações nem sempre favoráveis para a qualidade de todo o curso (SIPAÚBA-TAVARES, 1994).

O município de Presidente Prudente, localizado na região do Oeste Paulista $\left(22^{\circ}\right.$ 07' 04" S e 51 22' 57" W), possui cerca de 207.610 habitantes segundo o Instituto Brasileiro de Geografia e Estatística - IBGE (Censo 2010), e exerce influência sobre as cidades vizinhas desempenhando um papel de polo no ponto de vista do mercado consumidor e do mercado de trabalho. $\mathrm{O}$ seu sítio urbano é recortado por pequenos cursos d'água formadores dos córregos Cedro e Limoeiro, afluentes do Rio Santo Anastácio.

A princípio as áreas de fundo de vale da cidade eram ocupadas apenas por moradias de baixa renda, sem estruturas de saneamento básico. Somente a partir da década de 70 iniciou-se a reurbanização dessas áreas. Esse adensamento de moradias dessa faixa econômica, em áreas de preservação de fundos de vale, onde as condições físicas e ambientais são precárias e o solo é impróprio para a ocupação, é uma característica da urbanização brasileira (SÁNCHEZ; BELLO apud FELICIDADE et al., 
2001), um exemplo deste caso é o córrego do Veado, afluente do córrego do Limoeiro.

A ocupação das proximidades do córrego foi iniciada pela implantação de moradias de baixo poder aquisitivo. Porém, com o passar do tempo e com a intervenção política, foram realizadas ações para a valorização e revitalização da área, fazendo com que essa se tornasse o Parque do Povo, uma das maiores áreas recreativas da cidade (ALVES, 2004).

No entanto, o córrego do Limoeiro não foi levado para o mesmo caminho. Pelo contrário, teve sua APP cercada por alambrados com a intenção de evitar a entrada de pessoas, animais, e a deposição de resíduos, para que houvesse uma possível preservação do corpo d'água (SANTOS \& BARBOSA, 2013).

Desta forma, percebe-se a necessidade de analisar se o córrego do Veado, como afluente, é um agente causador de alterações na qualidade da água do córrego do Limoeiro.

Segundo Buss, Baptista e Nessimian (2003, p. 466) "o primeiro passo para a resolução dos problemas socioambientais gerados pela má gestão dos recursos hídricos é o desenvolvimento de metodologias de diagnóstico eficientes". A obtenção desses diagnósticos eficientes só é possível quando se dispõe de dados confiáveis a respeito das características do meio através da observação periódica destas, o que se resume a um monitoramento da qualidade da água (BRAGA; PORTO; TCCI apud REBOUÇAS; BRAGA, TUNDISI, 2002).

Segundo Tundisi e Tundisi (2008, p.20) "a limnologia é a ciência das águas interiores estudadas como ecossistemas". Logo, quando se busca um diagnóstico eficiente para a má gestão dos recursos hídricos urbanos, o monitoramento necessário dedica-se especificamente aos ecossistemas das águas continentais, tratando-se de um monitoramento limnológico (MAROTTA et al., 2007).

Através de um monitoramento torna-se possível observar a tendência da qualidade da água e a forma com que ela é afetada através de diversos fatores, tanto antrópicos, como naturais (GASTALDINI; MENDONÇA, 2001). Para que o monitoramento obtenha um resultado eficiente é necessário que haja um planejamento das atividades, de forma periódica e que essas sejam realizadas acompanhando também os fatores vinculados a impactos ambientais sobre o objeto de estudo, além de basear-se sempre na percepção contextualizada de métodos e teorias renomadas (CERQUEIRA et al., 2005). A própria utilização de cursos d'água por humanos só deveria ser planejada e concebida a partir da confirmação da possibilidade de seu uso através do 
monitoramento limnológico (MAROTTA; SANOTS; ENRICH-PRAST, 2008).

Há casos em que apenas a análise do comportamento das variáveis limnológicas em separado não é capaz de explicar a dinâmica dos ecossistemas aquáticos continentais. Em estudos limnológicos, teorias ecológicas ajudam a elucidar sobre a dinâmica desses ecossistemas revelando tendências e comportamentos espaciais e temporais de variáveis limnológicas

Atualmente, existem hipóteses primárias sobre o funcionamento de sistemas lóticos (JOHNSON; RICHARDSON; NAIMO, 1995) como o Conceito da Continuidade dos Rios (VANNOTE et al., 1980) que se refere às interações longitudinais dos canais, que representam as interações entre a cabeceira do rio e seus afluentes com o rio principal.

Outras duas dimensões, além dessas citadas, elucidam o entendimento funcional dos sistemas fluviais: a dimensão temporal, associada às variações nos processos conduzidos pelas variações hidrodinâmicas ao longo do tempo, sejam sazonais ou de maiores espaços de tempo, e as interações verticais, associadas aos fluxos subterrâneos e corredores hiporrêicos.

Neste contexto, Poole (2002) propõe o Conceito de Imparidade com o Descontínuo Fluvial. Nesse conceito os rios são assumidos como sistemas ímpares, isto é, únicos em estrutura e função na escala de bacia hidrográfica. Uma bacia é formada por manchas que são as características de cada segmento (como vegetação, sedimentos, fluxo, solo, etc.), e a dinâmica dessas manchas ao longo do sistema é que caracteriza o rio. Além das barragens e de outros empreendimentos, o papel dos tributários é considerado como grande fator de interferência no gradiente longitudinal do rio (BARBOSA \& ESPÍNDOLA, 2003).

Diante do exposto, a presente pesquisa propôs analisar o Descontínuo Fluvial no córrego do Limoeiro após a confluência com o seu tributário, o Córrego do Veado, ambos no município de Presidente Prudente/SP.

\section{METODOLOGIA}

O monitoramento limnológico foi realizado em dezembro de 2013, janeiro, maio e junho de 2014. As medições foram realizadas nas superfícies das três seções amostrais, sendo duas no córrego do Limoeiro (canal principal) e uma no córrego do Veado (tributário), ambos no município de Presidente Prudente/SP.

A primeira seção (S1) localizou-se no córrego do Veado, nas coordenadas $22^{\circ}$ $6^{\prime} 42.33^{\prime \prime S}$ e $51^{\circ} 26^{\prime} 46.31^{\prime \prime O}$. A segunda seção (S2) localizou-se no córrego do Limoeiro, a montante da confluência com o córrego do Veado, nas coordenadas $22^{\circ} 6^{\prime} 35.77^{\prime \prime} \mathrm{S}$ e 5126'53.77"O. A terceira seção (S3) localizou-se no córrego do Limoeiro, a 
jusante da confluência com o córrego do Veado, nas coordenadas $22^{\circ} 6^{\prime} 47.70^{\prime \prime} \mathrm{S}$ e $51^{\circ} 27^{\prime} 4.19^{\prime \prime O}$.

A Figura 1 apresenta as seções amostrais onde foi realizado o monitoramento limnológico.

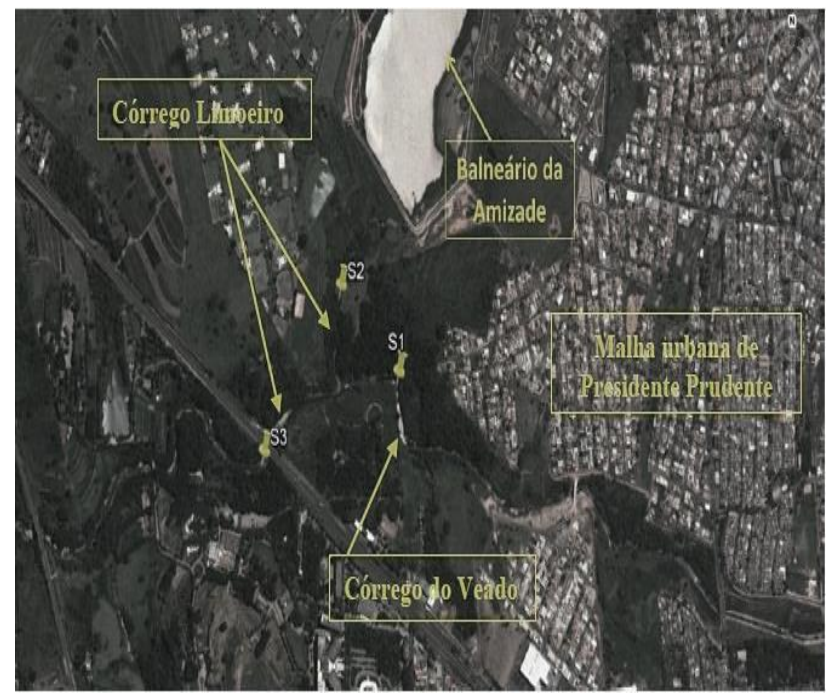

Figura 1. Seções amostrais: primeira seção (S1), córrego do Veado; segunda seção (S2), córrego do Limoeiro e terceira seção (S3), córrego do Limoeiro.

As variáveis limnológicas amostradas em campo foram o oxigênio dissolvido (OD), $\mathrm{pH}$, condutividade elétrica (CE), nitrato ( $\mathrm{N}$ NO3), temperatura da água (T) e turbidez (Turb). A medição destas variáveis foi realizada através de uma multisonda paramétrica da marca Hanna Modelo HI9829.

A determinação da vazão foi realizada em duas etapas: na primeira, fez-se uma batimetria da seção do rio, possibilitando o cálculo da área da seção. Na segunda etapa determinou-se a velocidade do rio em vários pontos da seção. Para o cálculo da velocidade do rio, mediu-se com uma trena uma distância de 1 metro, posicionou-se um material flutuante no ponto zero de distância e com um cronômetro contou-se o tempo que o material flutuante levou para percorrer a distância de 1 metro. Sabe-se que:

Área $=\operatorname{largura}(\mathrm{m}) \times$ profundidade $(\mathrm{m})$

Velocidade $(\mathrm{m} / \mathrm{s})=$ distância $(\mathrm{m}) /$ tempo (s)

Logo, vazão do rio foi ser determinada pela relação:

$Q=A \cdot V m(1)$

onde:

Q: vazão média do rio

A: área transversal do rio na seção de medição

Vm: velocidade média na seção.

Para o desenvolvimento dos protocolos laboratoriais, amostras de água foram coletadas nas seções amostrais e preservadas em caixas de isopor, armazenadas em frascos de polietileno $(5 \mathrm{~L})$.

Em laboratório amostras de águas foram filtradas em membranas Whatman GF/C, previamente calcinadas, e os filtros foram armazenados em freezer a $-20 \circ \mathrm{C}$ para posterior determinação das concentrações de material em suspensão total de acordo com Wetzel e Likens (1991). A água filtrada também foi preservada em freezer a -20 드, em frascos de polietileno $(500 \mathrm{ml})$, para posterior determinação das formas dissolvidas de fósforo dissolvido e fósforo reativo solúvel. Da mesma forma, a água não 
filtrada foi preservada em freezer a $-20 \circ \mathrm{C}$, em frascos de polietileno $(500 \mathrm{ml})$, para posterior determinação das concentrações de fósforo totais.

As membranas GF/C foram analisadas por gravimetria para determinação das concentrações de material em suspensão de acordo com Wetzel e Likens (1991). As frações de fósforo total e de fósforo dissolvido foram quantificadas após a digestão, na presença de um catalisador, em autoclave e posterior reação com adição de reagente misto (molibdato de amônia, tartarato de antimônio e potássio e ácido ascórbico) e leitura em espectrofotômetro a $882 \mathrm{~nm}$, de acordo com Mackereth, Heron e Talling (1978). O fósforo reativo solúvel ou orto-fosfato também foi obtido após reação com molibdato de amônia, tartarato de antimônio e potássio e ácido ascórbico e posterior leitura em espectrofotômetro a 882 $\mathrm{nm}$, de acordo com Mackereth, Heron e Talling (1978).

Os resultados do monitoramento foram tabulados e a análise de componentes principais (ACP) (ver GAUCH, 1994) foi aplicada com o objetivo de reduzir a dimensionalidade dos dados e avaliar padrões na ordenação espacial. Os valores dos parâmetros limnológicos, exceto os do $\mathrm{pH}$, foram logtransformados (base dez), para linearizar as relações e reduzir o efeito de valores elevados. Para avaliar os eixos a serem retidos para interpretação foi utilizado o modelo de "broken-stick" (JACKSON, 1993).

\section{RESULTADOS}

A análise de componentes principais resumiu o conjunto das variáveis ambientais escolhidas para o estudo e utilizando o modelo de "broken-stick", os componentes principais 1 e 2 foram significativos e, portanto, retidos para a interpretação dos dados limnológicos. Estes dois componentes explicaram $68,51 \%(\mathrm{CP} 1=52,37 \%$ e $\mathrm{CP} 2=$ $16,14 \%)$ da variabilidade total dos dados.

A ACP evidenciou tendência espacial do sistema e pôde-se observar que a variável positivamente correlacionada com o componente principal 1 foi o oxigênio dissolvido e que as negativamente correlacionadas foram a condutividade elétrica, o nitrato, o fósforo total, o fósforo dissolvido e o ortofosfato. Já a vazão correlacionou-se positivamente com o componente principal 2, enquanto o material em suspensão correlacionou-se negativamente com este (Tabela 1 ). 
Tabela 1. Coeficientes de estrutura derivados da análise de componentes principais aplicada aos dados limnológicos.

\begin{tabular}{|c|c|c|}
\hline Variáveis & CP1 & CP2 \\
\hline pH & $-0,225806$ & 0,628055 \\
\hline O.D. $\left(m g . L^{-1}\right)$ & 0,864950 & 0,085733 \\
\hline C.E. $\left(\mu\right.$ S. $\left.\mathrm{cm}^{-1}\right)$ & $-0,938024$ & 0,067423 \\
\hline Temp. (으) & $-0,044254$ & $-0,094345$ \\
\hline Turb. (UNT) & 0,578848 & $-0,313910$ \\
\hline$Q\left(m^{3} \cdot s^{-1}\right)$ & $-0,613909$ & 0,702559 \\
\hline MST (mg..$\left.^{-1}\right)$ & $-0,144935$ & $-0,752752$ \\
\hline Nitrato (mg. $\mathrm{L}^{-1}$ ) & $-0,925780$ & 0,074521 \\
\hline Fósf.Total(mg. $\left.\mathrm{L}^{-1}\right)$ & $-0,935650$ & $-0,259042$ \\
\hline Fósf.Dis. (mg. L $\left.^{-1}\right)$ & $-0,891564$ & $-0,250944$ \\
\hline Ortofosfato $\left(\mathrm{mg} \cdot \mathrm{L}^{-1}\right)$ & $-0,905291$ & $-0,257963$ \\
\hline
\end{tabular}

Tais coeficientes expressam as correlações de Pearson entre as variáveis e os componentes principais (CP1, CP2). Os valores maiores que 0,70 (em módulo) estão em negrito, identificando os coeficientes de estrutura mais correlacionados com os componentes principais 1 e 2 .

O gráfico da tendência espacial das seções amostradas gerado pela ACP está disposto na Figura 2.

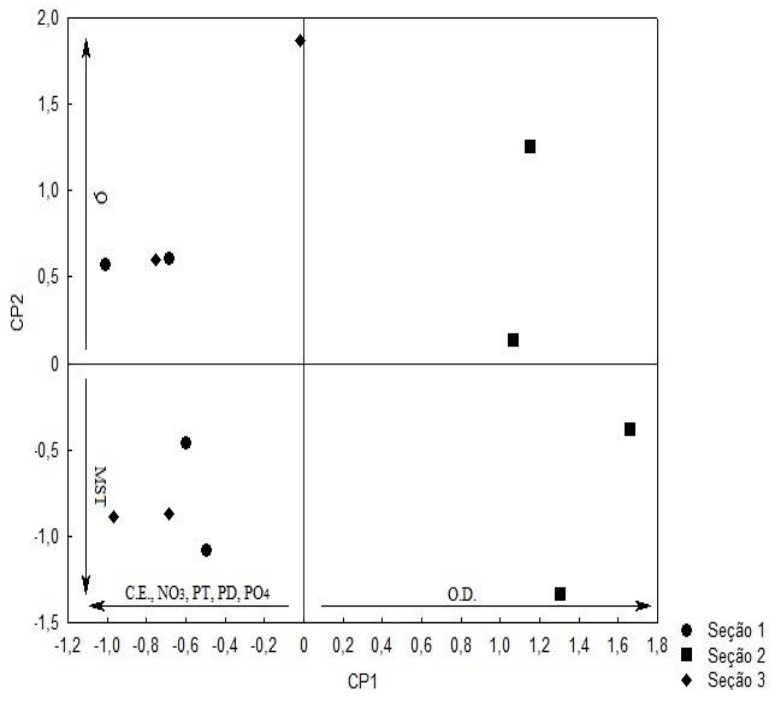

Figura 2. Análise de componentes principais. Ordenação espacial em função das seções que foram amostradas (tendência espacial).

Analisando as variáveis correlacionadas com o componente principal 1, observou-se que elas expressam um gradiente de trofia. Este gradiente de trofia refletiu-se na separação dos ambientes amostrados. Os ambientes com maiores valores de nutrientes foram aqueles que apresentaram menores valores de oxigênio dissolvido.

Os maiores valores de nitrato e das frações de fósforo encontrados na seção 1 , córrego do Veado, e em não conformidade com a legislação ambiental, podem ser explicados pelo fato de que o córrego atravessa a malha urbana do município de Presidente Prudente recebendo diferentes despejos líquidos e consequentemente tendo uma consequência negativa e provavelmente sinérgica. Em verificação de campo pôde-se observar ao longo do canal fluvial, a 
montante da S1 o lançamento de esgoto doméstico clandestino e efluente industrial clandestino. Vale ressaltar a possibilidade dos efeitos de sinergia também em consequência dos efluentes industriais tratados que são lançados no córrego, a saber: efluente líquido de um frigorífico e efluente líquido proveniente de dois curtumes. Segundo Von Sperlin (1996), o esgoto doméstico é a maior fonte de contribuição de fósforo e está presente nas fezes humanas, detergentes e outros subprodutos das atividades humanas. Dessa mesma forma, a presença de nitrato em corpos d'água representa indícios de lançamentos de esgotos domésticos e industriais (CAMPOS; ROHLFS, 2010). Além disso, o valor elevado de condutividade elétrica, $1.205 \mu \mathrm{S} . c m-1$, encontrado no curso d'água também representa indícios de poluição.

O córrego do Limoeiro (S2), à montante de sua confluência com o córrego do Veado, apresentou-se com maiores valores de oxigênio dissolvido e menores valores de nutrientes. Aparentemente a seção não encontra nenhuma inadequação na qualidade de sua água, o que se deve, provavelmente, à constante tentativa de preservação do corpo d'água. O alto teor de oxigênio dissolvido nesta seção pode ser relacionado ao fato de haver um trecho encachoeirado do canal fluvial a montante da seção 2, ver Figura 3. 


\section{CONSIDERAÇÕES FINAIS}

As águas do córrego do Veado são impactadas por ações antrópicas. E em consequência, o córrego do Veado confere mudanças negativas às características físicas, químicas e biológicas do córrego do Limoeiro, o que evidencia o Conceito de Imparidade com o Descontínuo Fluvial, constatando que o tributário provoca ruptura no gradiente contínuo natural do canal principal.

\section{AGRADECIMENTOS}

À Fundação de Amparo à Pesquisa do Estado de São Paulo, processo no 2013/17652-0, pela bolsa de iniciação científica.

\section{REFERÊNCIAS}

ALVES, A. O., 2004. Planejamento ambiental urbano na microbacia do córrego da Colônia Mineira - Presidente Prudente/SP.

BARBOSA, D. S. \& ESPINDOLA, E. L. G. . Algumas teorias ecológicas aplicadas a sistemas lóticos. In: Brigante,J.; Espindola, E. L. G.. (Org.). Limnologia fluvial: um estudo no rio Mogi-Guaçu.. São Carlos - SP: Rima Editora, 2003, p. 11-18.

BRAGA, B.; PORTO, M.; TUCCI, C.E.M. Monitoramento de quantidade e qualidade das águas. In: REBOUÇAS, A.C.; BRAGA, B.; TUNDISI, J.G. (Org.). Águas doces no Brasil: capital ecológico, uso e conservação. 2. ed. São Paulo: Escrituras, 2002.

BUSS, D.F.; BAPTISTA, D.F.; NESSIMIAN, J.L. Bases conceituais para a aplicação de biomonitoramento em programas de avaliação da qualidade da água de rios. Cadernos de Saúde Pública, Rio de Janeiro, mar-abr, 2003.

CAMPOS, T. S. \& ROHLFS, D. B.. Avaliação dos valores de nitrato em águas subterrâneas e sua correlação com atividades antrópicas no município de águas lindas de Goiás. Pontifícia Universidade Católica de Goiás, 2010.

CERQUEIRA, E. C.; D’ÁVILA, J. S. \& SANTOS, J. M.. Diagnóstico hidrológico e proposta para monitoramento dos recursos hídricos superficiais da bacia hidrográfica do Rio Paraguai - SSA/BA/BRASIL. Anais do $X$ Encontro de Geógrafos da América Latina, 2005. 23

GOMES, P. M.; MELO, C.; VALE, V. S., 2005. Avaliação dos impactos ambientais em nascentes na cidade de Uberlândia-MG: análise microscópica. Sociedade \& Natureza, Uberlândia, 17 (32): 103-120.

GASTALDINI, M. do. C. C \& MENDONÇA, A. S. F. Conceitos para a avaliação da qualidade da água. Porto Alegre: ABRH, 2001.

GAUCH, H.G., 1994. Multivariate analysis in community ecology. Cambridge: Cambridge University Press. 298p.

JACKSON, D., 1993. Stopping rules in principal component analysis: a comparison of euristical and statistical approaches. Ecology, 74, 2204-2214. http://dx.doi.org/10.2307/1939574

JOHNSON, L.J.; RICHARDSON, W.B.; NAIMO, T.J. Past, present, and future concepts in large river ecology. BioSciece, v.45, n.3, 1995.

MADRUGA, F.V. et al. Avaliação da influência do córrego dos Macacos, na qualidade da água do rio Mogi Guaçu, no município de Mogi Guaçu - SP. 2008. In: TERRA, V.R. et al. Estudo limnológico visando avaliação da 
qualidade das águas do rio Jucu Braço Norte, ES. Natureza online, n.8, p.8-13, 2010.

MACKERETH, F.Y.H.; HERON, J.G.; TALLING, J. Water analysis: some revised methods for limnologists. Fresh. Biological Associat. Publ., 36, 1978.

MAROTTA, H.; SANTOS, R. O.; ENRICH-PRAST, A., 2008. Monitoramento limnológico: um instrumento para a conservação dos recursos hídricos no planejamento e na gestão urbano-ambientais. Ambiente \& Sociedade, Campinas, v. XI, n. 1, p. 67-79. http://dx.doi.org/10.1590/S1414$\underline{753 \times 2008000100006}$

NAIME, R. \& FAGUNDES, R. S., 2005. Controle da Qualidade da Água do Arroio Portão. Instituto de Geociências, UFRGS, Porto Alegre, RS - Brasil.

POOLE, G. C., 2002. Fluvial landscape ecology: addressing uniqueness within the river discontinuum. Freshwater Biology, 47: 641-660p. http://dx.doi.org/10.1046/j.13652427.2002.00922.x

SÁNCHEZ, P.S.; BELLO, E.A.D. Ocupação periférica de baixa renda em áreas de mananciais. In: FELICIDADE, N.; MARTINS, R. C.; LEME, A.A. Uso e gestão dos recursos hídricos no Brasil. São Carols: RiMa, 2001.

SANTOS, F. R. \& BARBOSA, H. P, 2013. Um estudo comparativo de dois córregos urbanos em Presidente Prudente (SP): Colônia Mineira e Limoeiro. Geografia em Atos, n.13, vol. 2, p.69-89.

SIPAÚBA-TAVARES, L. H. Limnologia aplicada à aqüicultura. Jaboticabal: FUNEP, 1994. 70p. (Boletim Técnico do CAUNESP, n.1)

TUNDISI, J.G.; TUNDISI, T.M. Limnologia. São Paulo: Oficina de Textos, 2008.
VANNOTE, R.L. et al. The river continuum concept. Can. J. Fish. Aquat. Sci., v.37, p.130137, 1980. http://dx.doi.org/10.1139/f80-017

VON SPERLING, M. Introdução à qualidade das águas e ao tratamento de esgotos. DESA-UFMG.1996

WETZEL, R.G.; LIKENS, G.E. Limnological Analysis. 2. ed. New York: Spring Verlag, 1991. 